\title{
Transistorized timer for sensory-behavioral research
}

THOMY H. NILSSON, 1

Edmonton, Alberta, Canada

UNIVERSITY OF ALBERTA,

A timer circuit is presented that can produce pulse durations ranging from .I to $20,000 \mathrm{msec}$. The timer has high reliability, is inexpersive, and simple to construct.

The author's research on sensory processes called for the production of temporal durations in the millisecond range to control stimuli and the production of temporal durations in the multisecond range to control stimulus sequences (Nílsson, 1969). Operant research techniques have similar requirements for the control of stimulus and intertrial variables. While modular digital components can meet these requirements, they require extensive interfacing and are not as easy to use as individual commercial timers. The main drawback of some commercial timers is their unavailability in the millisecond range, together with the expense involved when large numbers of timers are needed to control multiple-choice stimulus sequences. For our research, a single timer was sought that would cover this wide range of temporal durations and provide a maximum flexibility of use and interchangeability of timers. It also had to be highly accurate and reliable, yet simple and inexpensive to build.

Humblet (1964) presents a circuit that meets some of these requirements. In particular, the use of the recently developed unijunction transistor to switch a flip-flop logic circuit offers a great range of pulse durations together with good stability. Pulse duration is determined by the time required to charge, through a resistor, the unijunction's emitter biasing capacitor to firing potential. By using several sizes of biasing capacitors and varying the charging resistance, one can vary the pulse duration. Since the circuit is triggered by a positive-going input, the negative pulse output can directly trigger similar circuits at the end of its duration.

Humblet's circuit was modified in the following manner. A Beckman Helipot $470 \mathrm{~K}$, linear, 10-turn potentiometer was substituted for the charging resistor. The setting of the potentiometer was indicated by a Spectrol Multidial Model 10 10-turn dial with three-figure decimal plus fractions readout. A potentiometer, as opposed to decade resistors, was chosen because it could be calibrated to produce any duration, it could easily be recalibrated under new conditions, and it resulted in simpler construction. The range of the potentiometer reflected a compromise between the requirement for a wide range of durations and the need for low variability at each setting. While long durations could be produced by resistance values above $1000 \mathrm{~K}$, these were found to be too sensitive to other factors for high reliability.

Similar problems were encountered in selecting the unijunction biasing capacitor values. With $100 \mathrm{~K}$ resistances, capacitors up to $20 \mu \mathrm{F}$ produced durations up to $20 \mathrm{sec}$ with day-to-day variability of less than $1 \%$, but larger capacitances were too sensitive. For reliability, the use of mylar (or polystyrene) capacitors was necessary, especially at long durations, to minimize variations due to dc leak. Four mylar capacitors of $.022, .22,1$, and $10 \mu \mathrm{F}$ were substituted for the single biasing capacitor. A four-position switch selected the capacitor for time ranges of 1 to 10,10 to 100,100 to 500 , or 500 to $5000 \mathrm{msec}$ on the potentiometer dial.

An indication of the functioning state of the timer was obtained by adding a TS49 lamp to each side of the flip-flop. Humblet's diode D3 was eliminated as an unnecessary source of
Table I

List of Parts for Transistorized Tiner.

\begin{tabular}{|c|c|c|c|}
\hline \multirow{5}{*}{$\begin{array}{l}\frac{\text { Part }}{\text { transistors }} \\
\text { unijunction } \\
\text { diodes } \\
\text { resistors }\end{array}$} & \multicolumn{2}{|c|}{ Manufacturer ${ }^{1}$ \& Description } & \multirow{2}{*}{$\frac{\begin{array}{c}\text { No. } \\
\text { Required }\end{array}}{2}$} \\
\hline & $2 N 1305$ & Texas Instruments & \\
\hline & $2 \mathrm{~N} 1671 \mathrm{~B}$ & Texas Instruments & $i$ \\
\hline & $1 \mathrm{~N} 191$ & General Llectric & 2 \\
\hline & $56 \mathrm{ohm}$ & Ohmitc "Little Devil" $1 \mathrm{~W}, \pm 5 \%$ & i \\
\hline & 100 & Ohmite "Little Devil" $1 / 2 W, \pm 5 \%$ & 1 \\
\hline & 270 & Ohmite Type $378810 \mathrm{~W}$ & 2 \\
\hline & $1.2 \mathrm{~K}$ & Ohmite "Little Devil" I $\mathrm{W}_{\mathrm{N}} \pm 10 \%$ & i \\
\hline & $6.2 \mathrm{~K}$ & Ohmite "Little Devil" "1// $\mathrm{W}, \pm 10 \%$ & 2 \\
\hline & $13 \mathrm{~K}$ & Ohmite "Little Devil" $1 / 4 \mathrm{~W}, \pm 10 \%$ & 2 \\
\hline \multirow{10}{*}{ capacitors } & $33 \mathrm{~K}$ & Ohmite "Little Devil" $1 / 4 W, \pm 10 \%$ & 2 \\
\hline & $200 \mathrm{pF}$ & & \\
\hline & $(.002 \mathrm{uuF})$ & Aerovox Type IDI & 2 \\
\hline & $.005 \mu \mathrm{F}$ & $\begin{array}{l}\text { Various makes and sizes used de- } \\
\text { pending on availability. Acrovos }\end{array}$ & \\
\hline & $.01 \mu \mathrm{F}$ & $\begin{array}{l}\text { Type VI6l } .005 \text { ul } 600 \mathrm{~V} \text { di or } \\
\text { Aerovox Type BPD .005 ul }\end{array}$ & 3 \\
\hline & $.03 \mu \mathrm{F}^{\prime}$ & capacitors can be used tor all three. & \\
\hline & $.022 \mu \mathrm{F}^{2}$ & Mallory Type PVC-1122 & 1 \\
\hline & $.22 \mu \mathrm{F}^{2}$ & Mallory Type PVC-1022 & 1 \\
\hline & $1 \mu \dot{F}^{2}$ & Acrovox Type PTT-87 & 1 \\
\hline & $10 \mu \mathrm{F}^{2}$ & Acrovox Type PTT-9? & $i$ \\
\hline potentiometer & $470 \mathrm{~K}$ & Beckman "Helipot", linear, 10-turn & $i$ \\
\hline & & Spectrol "Multidial" Model 10 & I \\
\hline lamps & & Chicago Miniature Lamps Type 49 & 2 \\
\hline \multirow{2}{*}{ lamp housings ${ }^{3}$} & (green) & Dialto Type $81-9110-0112-102$ & i \\
\hline & (amber) & Dialco Type $81-9110-0113-102$ & 1 \\
\hline range switch & & Stackpole Type SS-18, DP4T & 1 \\
\hline push switch & & Graybill Type $30-1$ & 1 \\
\hline \multirow[t]{2}{*}{ banana jacks } & & H. H. Smith Type 1505 , one each & \\
\hline & & of black, red, ycliow, and bluc & 4 \\
\hline \multirow[t]{2}{*}{ circuit board } & & Vector Type 64AA18 & \\
\hline & & $\begin{array}{l}\text { (enough for three) } \\
\text { Hammond "Hand "T }\end{array}$ & $1 / 3$ \\
\hline miscellaneous & & $\begin{array}{l}\text { Hammond Handibox lype } 1411 \mathrm{P} \\
\text { ers, and terminals }\end{array}$ & 1 \\
\hline
\end{tabular}

1. Manufacturer listed supplied the parts used bl author: other manufacturers may offer comparable components.

2. Other size capacitors can be selected to suit a particular time range requirement. Capacitors such as the Mallory. Type PVC (mylar).018 to $2 \mu \mathrm{F}, 200 \mathrm{~V} d \mathrm{~d}$ : Aerovox. Type PTT (polyester) 1 to $100 \mu \mathrm{F}, 25$ or $50 \mathrm{~V} d c$; or Aerovox, Type VI6l (polyester) .001 to $1 \mathrm{kF}$ would all be suitable jor stable performance at reasonable cost.

3. Lamp housings should accommodate a Size $31 / 2$ miniature bayonet base bulb.

temperature variation, though for very rapid recycling, a high-quality silicon diode could be used. A push switch was added for manual triggering. The components were wired onto a $4 \times 5$ in. epoxy card and mounted into a Hammond 141 IP metal box. The modified circuit is shown in Fig. 1 together with the layout of the front panel. Table 1 provides the parts list.

The circuit operates as follows: The two 2 N1305 transistors form a flip-flop subcircuit that is switched to an "operating" state by a "trigger input" and switched back to a "ready" state by the 2 N $1671 B$ unijunction. In the "ready" state, the left 2 N1305 conducts, keeping the right $2 \mathrm{~N} 1305$ nonconducting, and drives the left TS49 "ready" lamp to indicate that the circuit is ready to function. The end of a negative trigger pulse or the push and subsequent release of the manual trigger produce a positive-going voltage that briefly stops the left $2 \mathrm{~N} 1305$ from conducting. This causes a negative voltage to appear at the "output" of the circuit and permits the right 2 N 1305 to conduct. Once the right 2 N 1305 starts conducting, it keeps the left transistor nonconducting; it drives the right TS49 "operating" lamp to indicate that the circuit is producing a negative voltage at the "output"; and it 

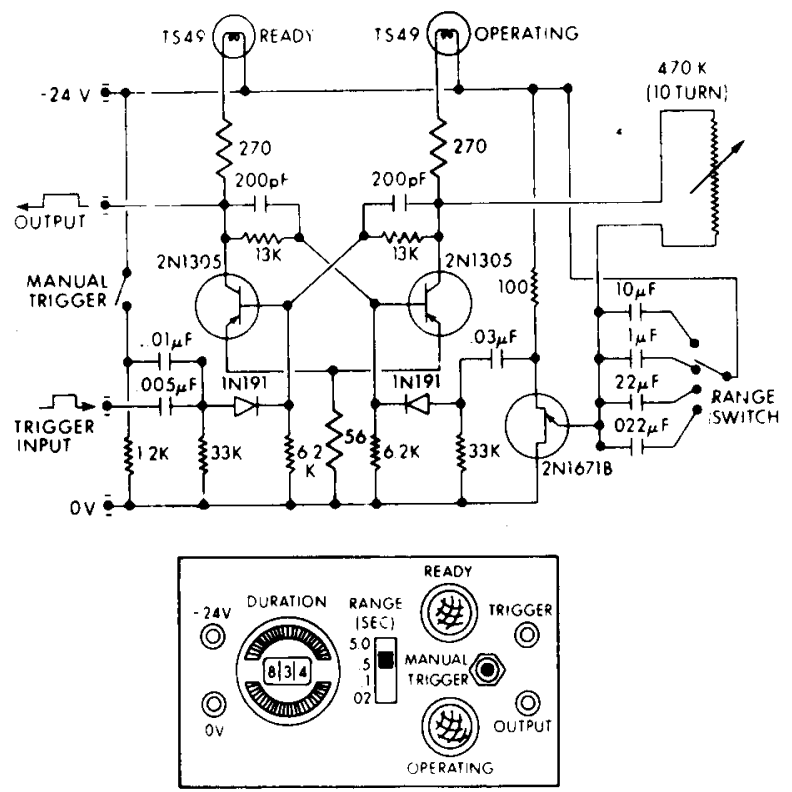

Fig. 1. Circuit diagram and front panel layout of timer.

charges, through the $470 \mathrm{~K}$ potentiometer, the selected unijunction biasing capacitor. When the charge on the biasing capacitor reaches the emitter firing potential, it briefly causes the unijunction to conduct. This results in a positive-going voltage that briefly stops the right $2 \mathrm{~N} 1305$ from conducting. As a result, the left 2 N1305 starts conducting again. This ends the negative voltage at the "output," keeps the right 2 N1305 nonconducting, and indicates that the circuit is "ready" to function again.

The modified circuit was tested to determine its stability in generating negative pulses with durations ranging from 1 to $5000 \mathrm{msec}$. Duration of the timer pulses was measured by a TSI Aptimeter Model 361 digital clock. Stability of the power supply was found to be a critical factor. During the tests and in subsequent use, the timers were powered by a Harrison Labs Mode 865 constant-voltage supply. Moment-to-moment variability was less than $1 \%$, while reset and week-to-week variability were less than $1 \%$ over the entire range of durations.

Eight identical timers of this design were built. In use, each timer was individually calibrated with a Tektronics Model 503 oscilloscope. During periods of several months' use, the timers showed no change in calibrations. When the timers were incorporated into new experiments, recalibrations were made to produce different duration settings as required. These timers have functioned for hundreds of hours over a 3-year period without failure except to replace two indicator lamps.

\section{$\operatorname{cosT}$}

The cost of parts for each unit was about $\$ 40.00$. The 10-turn potentiometer and precision dial comprised more than half of this amount. For applications which require no change in time duration, a simple 1-turn potentiometer (e.g., Clarostat Series RV4, 2-W carbon, 350K) and a knob would be sufficient and would cut the parts cost in half.

Each timer took about $8 \mathrm{~h}$ for a nontechnician to build. This time could be reduced. Humblet's layout was modified with a printed circuit application in mind. Printed circuits might be worthwhile for as few as 20 timers. For a sufficient demand, an electronics firm might be prevailed upon to offer circuit cards.

\section{REFERENCES}

HUMBLET, M. P. Design idea: Unijunction transistor multiplies monostable's pulse width. In S. Weber (Ed.), Modern digital circuits New York: McGraw-Hill, 1964. Pp. 70-71.

NILSSON, T. H. Two-pulse interval vision thresholds. Journal of the Optical Society of America, 1969, 59, 753-756.

\section{NOTE}

1. The author wishes to thank J. Brugman for his technical advice and for making available the facilities of Technical Services of the University of Alberta for construction and testing of these timers.

\section{A technique for the construction of discrete dichotic stimulation material}

\begin{abstract}
AUBREY J. YATES, PETER J. SMITH, BRYAN D. BURKE, and MAUREEN A. KEANE, UNIVERSITY OF WESTERN AUSTRAIIIA, Nedlands, Western Australia
\end{abstract}

Procedures are described for the generation, synchronization, and accurate spacing of discrete dichotic stimulation material. $A$ suggested standard definition of interpair interval is proposed.

The dichotic stimulation technique (the presentation of separate material simultaneously to each ear) has been extensively used since the impetus provided by Broadbent's original studies. The most common procedures have involved the use of sets of pairs of digits, letters, or words.

One of the important independent variables in the majority of these studies has been the rate of stimulus presentation. And this involves two problems: (I) the synchronization of the presentation (on stereophonic tape) of individual pairs, and
(2) the definition and achievement of a given presentation rate. A search of the literature reveals no standard solution for either of these problems. Thus, cross comparison of results of different studies is difficult.

Synchronization appears to have been achieved by recording the first digit on one channel and then attempting to line up the second digit on Channel 2 while monitoring the first by ear. With respect to the second problem, there appears to be little agreement as to what defines a given presentation rate. The rate is usually reported as the presentation of a given number of digit pairs in a given unit of time (e.g., two pairs per second). But the operations involved are seldom clear. Broadbent (1958), for example, states that "a pair of call signs arrived only every two seconds [p. 211]," and (1954) that "a $1 / 2$-sec interval was used between digits or pairs [p. 194]."

The techniques described in this paper are intended to provide: (1) a standard definition of the interpair interval, (2) methods for 